\title{
Effect of Malaria Incidence and Malaria Control on Health Outcome and Human Capital Development in Nigeria: An Econometric Analysis.
}

\author{
Victoria Hauwa Ibrahim \\ Department of Economics, Nasarawa State University \\ Keffi, Nasarawa State \\ Nigeria \\ Rabo M.D \\ E-mail: Dakarerabo@nsuk.edu \\ Eggon Henry Ahmed \\ E-mail: Henryeggon@gmail.com
}

\begin{abstract}
The study examined the effect of malaria incidence and malaria control on health outcome and human capital development in Nigeria for the period of 1991 to 2017. The Vector Error Correction Model (VECM) was employed for analyzing the objectives of the study which include to examine the effect of malaria incidence on adult mortality rate, under-five mortality rate, and human per capita income in Nigeria, and to examine the effect of malaria control on malaria incidence in Nigeria. The findings of the study revealed thatNigeria among other African nations is yet to fully achieve the objective of reducing the burden of malaria and effectively controlling the prevalence of malaria, thereby improving on positive health outcomes and sustainable national development, as the VECM analysis of empirical results showed that malaria incidence had a positive but minimal effect on adult mortality rate by $0.5 \%$, under-five mortality rate by $0.8 \%$, and human per capita income by $40 \%$. It also showed that malaria control which consists of children receiving anti-malarial drugs, government health expenditure, and insecticide-treated bed nets (ITNs) had a positive but poor effect on reducing the prevalence of malaria in Nigeria. As a result, the study recommends that the current National Malaria Control Programme (NMCP) should be strengthened and given more impetus in order to effectively control and combat malaria, the federal government of Nigeria should give major priority to the health sector in terms of spending as this will increase the provision of health facilities, storage facilities, and provision of appropriate anti-malarial medicines that will aid in controlling and reducing malaria incidence in Nigeria, among others were proffered.
\end{abstract}

Keywords: Malaria Incidence, Malaria Control, Mortality Rate, Human Per Capita Income, Vector Error Correction Model, Nigeria.

\subsection{Introduction}

Malaria is a disease primarily caused by a parasite called plasmodia of various types - Plasmodium ovale, Plasmodium malaria, Plasmodium vivax, and Plasmodium falciparium. Plasmodium falciparium is known to cause the most severe malaria illness and death worldwide. In 2008, Plasmodium falciparium accounted for 91 per cent of all 247 million human malarial infections (98 percent in Africa). It is known to be the most devastating in Nigeria (FMOH, 2010). The transmission of the parasite is facilitated through the bite of the female anopheles' mosquito.

Malaria ranks among the major health and development challenges facing some of the developing economies in Africa most especially in the Sub-Sahara Africa. In Sub-Sahara Africa, malaria-related illness claims the life of one out of every twenty children below the age of five. On the other hand, adult mortality rates are lower than infant mortality rates, but frequent debilitating attacks reduce the quality of life for chronic sufferers.

However, according to National Population Commission (2006 projected), Nigeria which is the most populous country in Africa with a projected total population of approximately 212 million for 2019 , bears up to 25 percent of the malaria disease burden in Africa, hence contributing significantly to the one million lives lost per year in the region, consisting mostly of children and pregnant women. Malaria-related deaths account for up to 11 percent of maternal mortality, 25 percent of infant mortality, and 30 percent of under-five mortality, resulting in about 300,000 childhood deaths annually. 
In addition, malaria overburdens the already-awakened health system in Nigeria as nearly 110 million clinical cases of malaria are diagnosed each year, and the disease contributes up to 60 percent of outpatient visits and 30 percent of admissions. Malaria also exerts a huge social and economic burden on families, communities, and the country at large, causing an annual loss of about $\$ 132$ billion in payments for treatment, control, and prevention as well as hours not worked (MIS, 2010; Jimoh, Sofola, Petu, \& Okorosobo, 2007).

The endemicity of malaria tends to impact negatively on household poverty, individual productivity, welfare, and human capital development in Nigeria. For instance, Nwanosike, Ikpeze, and Ugbor (2015) posited that more than half of the country's population lives below poverty line, given that the incidence of malaria may increase significantly in Nigeria. This may be as a result of the fact that majority of populace with the malaria disease may not be able to afford expensive medications due to poverty, and as such would lead to high mortality rate in Nigeria. Consequently, this has some negative implications for the achievement of economic developmental goals of the country, as well as key development blueprint in National Economic Empowerment and Development Strategies (NEEDS), Millennium Development Goals (MDGs) target, and Nigeria Vision 20:2020. For instance, it is estimated that the productivity and economic loses and opportunity costs due to malaria amount to 480 billion annually in Nigeria (FMOH, 2016).

However, medical and economic experts uphold the fact that reducing poverty among households and individuals, reducing mortality rate, improving human capital development, individual productivity and welfare, as well as aggregate national development in Nigeria (Nwanosike et al, 2015; Olalekan \& Nurudeen, 2013). Thus, in order to reduce the epidemic of malaria in Nigeria, its government needs to develop some control and prevention as well as dominating in health expenditure. This is because, the great chance of developing an economy like Nigeria where malaria is endemic depends on the ability to control the disease.

\subsection{Statement of the Problem}

Malaria is endemic in Nigeria, and children and pregnant women are at the highest risk of its total population. And, increase in the incidence of malaria also leads to the increase in morbidity and mortality rates, as well as social and economic loses. As posited by Tewari, Braimoh, and Bokana (2009), as malaria affects individuals and households through the economic costs imposed on them, it affects the wealth of the nation through absenteeism from work and hence productivity. In other words, as a result of malaria, children spend days away from school and adults lose workdays in Nigeria.

In relation to the incidence of malaria and mortality rate in Nigeria, from 2000 to 2010, the incidence of malaria (per 1,000 population at risk) increased from 378.26 cases to 383.09 cases (WDI, 2018). As a result, malaria has been reported to account for 60 percent of outpatient visits and 30 percent of hospitalizations among children under five years of age in Nigeria (NMCP, 2012). In this same period as a result of the prevalence of malaria, NMCP (2012) revealed that Nigeria accounts for 32 percent of the global estimate of 655,000 malaria deaths. Whereas in Nigeria, 157 children (per 1,000 live births) die before reading the age of five. From 2011 to 2017, the incidence of malaria (per 1,000 population at risk) declined from 371.63 cases to 281.15 cases (WDI, 2018). As a result, under-five mortality reduced from 187 in 2010 to 100 in 2017, while mortality rate for female adult (per 1,000 female adult) reduced from 425 in 2000 to 371 in 2017, and mortality rate for male adult (per 1,000 male adults) reduced from 387 in 2000 to 333 in 2017 (WDI, 2018).

However, despite the declining trend in malaria incidence and its mortality rates in Nigeria, it is obvious and evident that many deaths still occur among individuals and are not officially counted. As a proof, World Development Indicators (WDI) (2018) revealed that deaths resulting from malaria have been estimated at over 300,000 deaths per year in Nigeria, where malaria accounts for more deaths per year than HIV/AIDS, and is still the major contributor of deaths in children under-five years and in pregnant women.

Currently, studies show that the level of socio-economic development in a country usually affects how much is invested by the government in health care, which in turn affects the health outcomes and severity of diseases like malaria (Carrington, 2001; Nwanosike et al, 2015). Nigeria's 4.1 percent and 3.9 percent allocation of its annual national budget in 2017 and 2018 respectively to the healthcare sector is very low and has resulted in poor health outcomes, and an increase in the prevalence and severity of malaria disease (Ogiri, 2017). And as a result, this has not yet improved on the human capital development in terms of its low gross national income per capita of US\$360. In addition, as a way of controlling and preventing the prevalence of malaria in Nigeria, several malaria programmes have been established by the government which has been in existence since 1986 with the National Malaria Control Programme. According to Federal Ministry of Health (2017), substantial malaria control investments have been made in Nigeria in the last decade in the context of the National Malaria Strategic Plans, 2001-2005, 2006-2010, 2009-2013, 2014-2020, and 2015-2030. 
In order to initiate a more focused effort to reduce the burden of malaria, Nigeria joined other African nations in 2000 to set aside $25^{\text {th }}$ of April of every year to draw attention to the menace of malaria and to build support for its elimination. As a result, the day was tagged "World Malaria Day". The first plan by the National Malaria Elimination Programme covered the period 2001-2005 and was developed after the African Summit on Roll Back Malaria to build partnership. The second plan covered 2006-2010 and focused on vulnerable populations as the primary target groups for intervention were pregnant women, children of less than five years, and people living with HIV/AIDS. The third plan provided a road map for malaria control in Nigeria. The fourth plan covered 2014-2020 and it focused on preelimination and reduction of malaria related deaths to zero by 2020. The fifth plan covered 2016-2030 and it aims to reduce the global malaria disease burden by 40 percent by 2020 and by at least 90 percent by 2030 (FMOH, 2016; FMOH, 2017).

However, despite these efforts being put in place by the government in controlling and preventing malaria in Nigeria, several setbacks have been experienced which have made effective control and prevention of the disease very difficult, which in turn, have increased the malaria prevalence on under-five mortality rate, malaria deaths, low life expectancy, high government spending on health, reduction in labour efficiency and supply, low income and productivity. These setbacks include poor storage facilities to support Indoor Residual Spraying (IRS) commodities and activities, inequality in access to appropriate treatments with patients in rural areas, lack of access to malaria treatment guidelines, weak referral systems militating on quality of care for severe malaria, limited availability and utilization of Information, Education, Communication (IEC)/Behaviour Change Communication (BCC) materials, persistent stockouts of malaria commodities, lack of good storage infrastructure and practices (e.g. for Long-Lasting Insecticidal Nets), inventory control management and reporting in some health facilities. Consequently, these has not yet translated to a drastic reduction in malaria cases and mortality rate in relation with the intensified efforts and spending of the government on the health sector, especially against malaria.

It is on this note that this study therefore examines the effect of malaria incidence and malaria control on health outcomes and human capital development in Nigeria. The findings are expected to provide policy suggestions which could lead to improvement in the level of government participation in the effective control and prevention of malaria, as well as providing information on how the incidence and control of malaria has affected health outcomes (i.e. mortality rates) in Nigeria.

\subsection{Research Questions}

The following research questions seek to guide this study;

i. What is the effect of malaria incidence on adult mortality rate in Nigeria?

ii. What is the effect of malaria incidence on under-five mortality rate in Nigeria?

iii. What is the effect of malaria incidence on human per capita income in Nigeria?

iv. What is the effect of malaria control on malaria incidence in Nigeria?

\subsection{Objectives of the Study}

Broadly, the study seeks to examine the effect of malaria incidence and malaria control on health outcomes and human capital development in Nigeria. specifically, the study seeks to;

i. Examine the effect of malaria incidence on adult mortality rate in Nigeria.

ii.Examine the effect of malaria incidence on under-five mortality rate in Nigeria.

iii. Examine the effect of malaria incidence on human per capita income in Nigeria.

iv. Examine the effect of malaria control on malaria incidence in Nigeria.

\subsection{Scope of the Study}

The study is restricted to the period between 1991 and 2017 using relevant indicators such as incidence of malaria (per 1,000 population at risk), mortality rates (under-five mortality rate, adult-female mortality rate, and adult-male mortality rate), government health expenditure, per capita income, among others. The scope was chosen based on the current availability of data especially of the incidence of malaria which started from the year 1991 to 2017.

In addition, it was also based on the fact that Nigeria established her first National Malaria Strategic Plan (2001-2005) as a way of joining other African Nations in 2000 in making $25^{\text {th }}$ of April of every year as "World Malaria Day" in order to draw attention to the menace and control of malaria.

\subsection{Conceptual Framework}

\subsubsection{Epidemiology of Malaria in Nigeria}


According to Chukwu (2018) and Federal Ministry of Health (FMOH) (2017), malaria is a disease spread by the female Anopheles mosquito and is caused by a parasite known as plasmodium. According to them, the mosquito carries the parasite where it starts its life cycle. Once the parasites get into the human body, they travel to the liver where they mature after which the parasites get matured and enter the blood stream and begin to infect the red blood cells. Chukwu (2018) added that within 48 to 72 hours, the parasites inside the red blood cell multiply causing the infected cells to burst open usually resulting in development of symptoms like headache, fever, and vomiting. Therefore, malaria is not a communicable disease but can be spread without a mosquito (i.e. through blood transfusions).

The subspecies of the malaria parasite (plasmodium) as posited by Chukwu (2018) include Plasmodium falciparum, Plasmodium ovale, Plasmodium vivax, Plasmodium malarie, and Plasmodium knowlesi. However, the Plasmodium falciparum happens to be the most predominant specie of the malaria parasite in Nigeria with 97 percent of the total population at risk (FMOH, 2017).

Basically, malaria is a significant public health problem, with a high global burden leaving the Sub-Saharan Africa accounting for 90 percent of the malaria cases and 92 percent of the malaria deaths worldwide (WHO, 2018). Nigeria and Republic of Congo are two major African countries contributing to the high malaria burden, as 36 percent of the malaria case worldwide occurred in these two countries (DHS, 2014; WHO, 2016).

Nigeria is currently a malaria endemic country with its entire population (212 million) at risk of controlling malaria, and 76 percent of this population at high risk (NPC, 2006 projected). Over the years, malaria has remained one of the leading causes of death in Nigeria. For instance, according to PMI (2018), under-five mortality is estimated at 128 per 1,000 live births and maternal mortality is estimated at 576 per 100,000 live births. Aribodor, Ugwuanyi, and Aribodor (2016) posited that a larger proportion of the malaria cases that resulted in mortality likely occurred among children less than five years old. However, there has been a gradual decline in the prevalence of malaria among children in this age group over the years. For instance, from 2010 to 2015, prevalence of malaria among under-five years old children declined from 42 percent to 27 percent respectively (MIS, 2016). However, pregnant women living in places where malaria is highly prevalent are four times more likely than other adults to get malaria and twice as likely to die of the disease. Currently, malaria related deaths account for up to 11 percent of maternal mortality, 25 percent of infant mortality, and 20 percent of under-five mortality resulting in 300,000 childhood deaths annually (Aribodoret al, 2016; FMOH, 2017; Chukwu, 2018; PMI, 2018).

\subsubsection{Malaria Control and Prevention in Nigeria}

According to Maduka (2018), malaria control has been in existence since 1948, and the oldest control programme in Nigeria. the malaria control programme has gone through several transition from the National Malaria Service in 1948 to the National Malaria Control Programme in 1986, and to the National Malaria Elimination Programme in 2013 as a reflection of the country's desire for a malaria-free nation. In addition, substantial malaria control investments have been made in Nigeria in the last decade in the context of the National Malaria Strategic Plans (NMSPs) (FMOH, 2017). Maduka (2018) further posited that, four NMSPs have been in use with the latest being the National Malaria Strategic Plan for 2014-2020. This current plan presents a major scale up of key interventions, draws from a robust evidence base and the experience in previous years. It also aims to achieve pre-elimination status and reduction of malaria related deaths to zero by 2020 in Nigeria (FMOH, 2017; Chukwu, 2018).

On the other hand, there has been a number of efforts to prevent malaria transmission in Nigeria over the years. In Nigeria, effective malaria prevention methods as identified by PMI (2018) and Maduka (2018). Include the use of Insecticide-Treated Nets (ITNs) and Indoor Residual Spraying (IRS).

i) Insecticide-Treated Nets (ITNs): The NMSP for 2014-2020 targeted that the distribution of 63million ITNs by the end of 2020 will at least achieve 80 percent utilization. In 2015, 69 percent of households owned at least one insecticide treated net. The ownership of nets was 10 percent higher in rural areas than in urban areas. Majority of the households in owned 53 percent of the ITNs. Despite high rates of ownership of ITNs in Nigeria, only 37 percent of the households in Nigeria slept under their ITN in 2015. Less than half of the children aged below 5 years old (44 percent) slept under a mosquito net in 2015, and only half of the pregnant women slept under a mosquito net, even though they are extremely vulnerable to severe effects of malaria (MIS, 2015; PMI, 2018). This shows that ITNs utilization is yet to come to par with ITNs ownership. In other words, there is persistently lower rates for net utilization compared to ownership (Maduka, 2018).

ii) Indoor Residual Spraying (IRS): This involves the spraying of interior walls and ceilings of houses with a chemical to provide long last protection against mosquitoes. The IRS implementation programme is a relatively new programme in Nigeria, and is probably the reason why only one percent of households was sprayed with IRS in 
2015 (MIS, 2015). The reasons for this as Maduka (2018) posited may relate to the prohibitive cost of IRS campaigns, the absence of vector maps to guide implementation and the rising incidence of resistance of pyrethroids and other insecticides.

\subsection{Theoretical Framework}

This study is anchored on the Health Production Function Approach by Wibowo and Tisdell (1992). Basically, the production function is an equation in economics that expresses the relationship between the quantities of productive factors (i.e. labour and capital) used, and the amount of product obtained. This approach states the amount of product that can be obtained from every combination of factors, assuming that the most efficient available methods of production are used.

Brems (1968) and Hulton (2000) posited that aggregate production functions are estimated to create a framework in which to distinguish how much of economic growth to attribute to changes in factor allocation (i.e. the accumulation of physical capital), and how much to attribute to advancing technology. Specifically, a production function can be expressed in a functional form as in Equation [1]:

[1] $\quad Q=f\left(x_{1}, x_{2}, x_{3} \ldots \ldots, x_{\mathrm{n}}\right)$

Where $Q$ is the quantity of output; and $x_{1}, x_{2}, x_{3} \ldots \ldots, x_{\mathrm{n}}$ are the quantities of factor inputs (i.e. capital, labour).

According to Wibowo and Tisdell (1992), health production function describes the relationship between combination of health inputs, both medical and non-medical, and resulting health output. According to them, it shows how health inputs interact to produce a particular level of health, and how health status changes if health inputs used and their combination change.

Wibowo and Tisdell (1992) further expressed that to develop health production functions for a nation, indicators such as morbidity/incidence, mortality, the infant mortality rate of life expectancy can be used as a measure of a nation's health status. According to them, let $M$ represents morbidity of either a single disease (i.e. malaria) or a group of disease. In this respect, morbidity is considered to be a function of preventive health programs $(P)$, health care service $(C)$, community environment and habitat $(H)$, and socio-economic variables (E) (Grossman, 1972; Wagstaff, 1986).

$$
M=f(P, C, H, E, \mu)
$$

Where $M$ is the morbidity of disease(s) (i.e. malaria); $P$ is the preventive health programs; $C$ is the health care services; $H$ is the environment indicator of the country; $E$ is the socio-economic indicators, and $\mu$ is the unobserved health stock in the country otherwise known as error term.

Wibowo and Tisdell (1992) further posited that preventive health program $(P)$ may include immunization, insecticide spraying for vector-borne disease, surveillance for communicable disease, health promotion and education, nutrition improvement, promotion of breast feeding, investment in water supply and sanitation, etc. Health care services $(C)$ may include variables such as health expenditure, supply and the use of medical services, the level of medical technology, and the use of medicine in the nation. Environmental indicator $(H)$ may include variables such as sanitary living conditions, closeness to rivers, rainfall, and geographical features. Lastly, socio-economic indicators $(E)$ may include per capita income, education level, migration, etc.

However, unlike the usual production function in which output normally increases when the quantities of inputs used in the production process increase, in this case of health production function, the morbidity of disease(s) (i.e. malaria) decrease when the quantities of inputs used in the production of health increases. This also occurs when either overall mortality rate is employed as on output variable (Wibowo and Tisdell, 1992).

\subsection{Empirical Literature}

Jimoh (2000) used the production function approach to evaluate the malaria burden on the Nigerian agricultural sector. The findings showed that the economic burden of malaria, in terms of lost agricultural output, may be as high as \#3.953 million for every reported cases of malaria per 100,000 persons and therefore colossal. The findings generally revealed that the agricultural sector bears about 75 percent of the direct economic burden of malaria in Nigeria.

Jimoh, Sofola, Petu and Okorosobo (2007) employed the willingness to pay (WTP) approach to evaluate the burden of malaria in Nigeria. The findings indicated that households would be prepared to pay an average of about $\$ 1,112$ (USD9.3) per month for the treatment of malaria. Similarly, households are willing to pay on the average sum of N7,324 (USD61) per month for the control of malaria. This amount represents about $\$ 611.7$ (USD5.1) per head per month and $\$ 7,340$ (USD61.2) per year. The findings resulted to the fact that for a country with a population of about 
120 million this translates to about $\$ 880,801$ million per annum, representing about 12.0 percent of GDP. Hence, the malaria burden in Nigeria is enormous and has a devastating impact on economic growth.

Ajani and Ashagidigbi (2008) employed the stratified random sampling procedure to analyze the effect of malaria on the overall farm income of the rural household; the level of awareness, and use of modern preventive measures of treating malaria in Ido Local Government Area, Oyo State, Nigeria. A total number of 100 respondents were used for data analysis using both descriptive and multiple regression techniques. Findings of the study revealed low level of awareness $(59 \%)$, use of modern preventive measures (12\%), poor sanitary conditions and large household size (8 persons) were the major factors responsible for the high malaria incidence in the rural household in Oyo State. The findings also revealed that the increase in malaria incidence however had a significant effect on the health and farm income of the farmers through increase in the number of days of incapacitation of an average of 22 days and an income loss of 15231.50 during the days of incapacitation.

Amzat (2011) adopted the descriptive survey to assess the current malaria burden and progress toward malaria control in Nigeria. Substantial data for the study were obtained from the 2008 Nigeria Demographic and Health Survey and other secondary sources. The study revealed that the malaria burden is still enormous because of inadequate control efforts. Specifically, the study showed that in 2008, only $17 \%$ of Nigerians owned at least one net, compared with $12 \%$ in 2003; 8\% owned an insecticide-treated mosquito net (ITN), but only 6\% of under-five children and 5\% of pregnant women slept under an ITN. Lastly, only one third of under-five children with fever received anti-malarial drugs, while one fifth of pregnant women took anti-malarial drugs for prevention in Nigeria.

Usman and Adebayo (2011) adopted the binary response model of descriptive analysis to analyze the effect of malaria on productivity, household expenditure and mortality rate on households in Kwara State, Nigeria. The result obtained showed that differences in household costs of malaria are the product of complex relationships between social, economic and epidemiological factors. It further showed that malaria infection has negative effects on productivity; treatment cost of all household have a positive effect on private expenditure especially of the marginal groups, and malaria infection has a positive effect on mortality rate.

Olalekan and Nurudeen (2013) employed the cost of illness approach with a primary data analysis to evaluate the trend of malaria burden and the effectiveness of malaria control measures on Asa Local Government Area of Kwara State, Nigeria. A total of 1200 households were interviewed using a questionnaire for the analysis. The findings indicated that 37 percent of the population of the studied sample suffered malaria attack with a dependency ratio of 33percentage. It also revealed that the total private direct cost is $\$ 446,070$ billion, and total private indirect cost is $\$ 1,409,790$ billion. From the study, the total cost of malaria illness in Nigeria was estimated to be about $\$ 2,231.34$ billion representing 7.3 percent of the GDP in 2011. The findings also revealed that there has been a significant reduction in the burden of malaria on the economy when compared with the baseline study conducted in 2007.

Abatan and Batunde (2015) adopted the descriptive survey to empirically investigate the patterns and trends of occurrences of malaria cases in Ekiti State of Nigeria, and observed that interventions do not necessarily reduce malaria cases among hospitals categories in Ekiti State; as poor sanitation, lack of portable water, inadequate immunization and health education, malnutrition all accounted to malaria hazard.

Nmadu, Peter, Alexander, Koggie, and Maikenti (2015) analyzed the prevalence of malaria in children between the ages 2-15 visiting Gwarinpa General Hospital Life-Camp, Abuja, Nigeria using the descriptive survey technique. The findings of the study revealed that 128 children $(64 \%)$ were infected with malaria parasite, of the 200 children (215years) sample size, out of which children between the age of 2-5 were observed to have the highest percentage (29\%) of the infection followed by 6-10years and 11-15years respectively. Nyiataghor, Umeh, and Ocholi (2015) employed the descriptive statistics and household expenditure models to analyze the effects of malaria on households' consumption in North-Central Nigeria. A multistage sampling technique was used to collect data from 600 houses affected with malaria in North-Central Nigeria.

The study revealed that only $39 \%$ of the households in the study area had three meals per day during the period of malaria attack compared to $61.7 \%$ before malaria attack. The household expenditure models revealed a negative relationship between malaria attack and food expenditure, education expenditure, and housing expenditure. The study also revealed a positive relationship between health consumption of affected households and household income, borrowing, sale of assets, and de-saving in North-Central Nigeria. Abah, Awi-Waadu, Nduka, and Richard (2017) adopted the descriptive technique to investigate the prevalence of malaria and socio-economic status of subjects' impact of PortHarcourt metropolis. A total number of 200 respondents were used for data analysis. Findings revealed that there was overall prevalence of malaria by 71 (35.5\%) of the total sample population. Sex related prevalence 
showed that more males were infected with $42(40 \%)$ and parasite density of $91120 \mu 1$ than females with $29(30.5 \%)$ and parasite density of $62480 \mu \mathrm{l}$. The prevalence of malaria infections based on socio-economic status showed that greater percentage of infection of $55(38.2 \%)$ was recorded among the higher class with parasite density of $112880 \mu 1$, followed by infection of $12(35.3 \%)$ and parasite density of $29120 \mu$ in the lower class with the least percentage of 4 $(18.2 \%)$ and parasite density of $11600 \mu 1$ recorded in the middle class.

Adepoju and Akpan (2017) examined the historical trend and anomaly of malaria cases and mortality in Nigeria spanning a period of sixty years. The result shows that malaria prevalence increased significantly between 2000 and 2015, and most of the cases were found among children and women. It was also found that malaria distribution in Nigeria may experience a shift towards the North-Central region due to complex environmental, social and demographic factors.

However, most of the studies reviewed focused only the impact of malaria incidence on households on specified locations in Nigeria without examining its aggregate impact of the epidemic on the entire country (Usman and Adebayo, 2011; Nyiatagheret al, 2015; Ajani and Ashagidigbi, 2008; Abahet al, 2017; Olalekan and Nurudeen, 2013; Abatan and Batunde, 2015; Nmaduet al, 2015). In addition, only Amzat (2011) among the reviewed studies investigated into the progress of malaria control and the extent of government intervention on malaria prevalence in Nigeria from the year 2000 to 2008 .

In carrying out the impact analysis of malaria incidence and malaria control on health outcomes in Nigeria, all of the reviewed studies adopted the descriptive survey methods of analysis without employing the secondary data analysis which entails specific estimation techniques like the Vector Error Correction Model (VECM). Also, none of the reviewed studies employed the time-series data covering the period from 2000-2017 which is major focus of the study. To overcome this shortfall, the study therefore adopts the annual time series data from 2000 to 2017 and employs the Vector Error Correction Model (VECM) estimation technique to examine the effect of malaria incidence and malaria control on health outcome and human capital development in Nigeria using relevant indicators such as incidence of malaria (per 1,000 population at risk), under-five mortality rate, adult mortality rate, government health expenditure, per capita income, use of insecticide-treated bed nets, and children with fever receiving anti-malaria drugs in Nigeria.

\subsection{Methodology}

The study adopts the Vector Error Correction Model (VECM) which was used to examine the effect of malaria incidence and malaria control on health outcome and human capita development in Nigeria. The secondary data adopted for the analysis covered the period from 1991 to 2017. In achieving the objectives of this study, relevant data which were obtained from World Development Indicators (WDI) (2018), Federal Ministry of Health (FMOH) (2017), CBN statistical bulletin (2017), and World Health Organization (WHO) (2016) were also analyzed by utilizing the Eviews econometric software version 10.0.

In achieving the effect of malaria incidence and malaria control on health outcome and human capital development in Nigeria, the study adopted the production function framework and modifies the empirical work of Jimoh (2000) and,Wibowo and Tisdell (1992) where morbidity of a disease is considered to be a function of preventive health programs, health care services, community environment, and socio-economic variables as speculated in Equation [2]. The new production function model for this study introduced malaria incidence as the dependent variable, and underfive mortality rate, adult mortality rate, government health expenditure, use of ITNs, children with fever receiving antimalarial drugs, and per capita income as the independent variables. Hence, the implicit form of the production function is presented in Equation [3] as:

$$
I M A=f(U M R, A M R, G H E, I T N, C F A, P C I)
$$

Where IMA is incidence of malaria (per 1,000 population at risk); UMR is under-five mortality rate (per 1,000 live births); $A M R$ is adult mortality rate (per 1,000 male and female adults); GHE is government health expenditure; ITN is use of insecticide-treated bed nets (\% of under-five population); $C F A$ is children receiving anti-malarial drugs (\% of under-five children); and $P C I$ is per capita income. Specifically, $U M R$ and $A M R$ are proxied for health outcome; GHE, $I T N$, and $C F A$ are proxied for malaria control; while $P C I$ is proxed for human capital development in Nigeria.

The implicit function in Equation [3] can be reduced to a linear functional form as in Equation [4]:

[4] $I M A=a_{0}+a_{1} U M R+a_{2} A M R+a_{3} G H E+a_{4} I T N+a_{5} C F A+a_{6} P C I+\mu$

Where $a_{0}$ is the intercept; $a_{1}-a_{6}$ are the coefficients of all the explanatory variables, and $\mu$ is the error term. 


\subsection{Model Specification of the Study}

The Vector Error Correction Model (VECM) was employed in achieving the objectives of the study. A VECM like the Vector Autoregression (VAR) model is an $n$-equation, $n$-variable model in which each variable is in turn explained by its own lagged values, plus the current and past values of the remaining n-1 variables. A typical VECM model is specified in Equation [5] as:

$$
Y_{t}=c+b_{1} Y_{t-1}+b_{2} Y_{t-2}+\ldots . .+b_{p} Y_{t-p}+e_{t}
$$

Where $Y_{t}$ are the variables in the VECM model, $e_{t}$ is the error term, and $b_{1}, b_{2}, \ldots \ldots, b_{p}$ are the coefficient of the variables. Therefore, Equation [4] can be expressed in VECM form as thus;

[6] $I M A_{\mathrm{t}}=b_{0}+b_{1} I M A_{t-1}+b_{2} U M R_{t-1}+b_{3} A M R_{t-1}+b_{4} G H E_{t-1}+b_{5} I T N_{t-1}+b_{6} C F A_{\mathrm{t}-1}+b_{7} P C I_{t-1}+e_{\mathrm{t}}$

[7] $U M R_{t}=a_{0}+a_{1} I M A_{t-1}+a_{2} U M R_{t-1}+a_{3} A M R_{t-1}+a_{4} G H E_{t-1}+a_{5} I T N_{t-1}+a_{6} C F A_{t-1}+a_{7} P C I_{t-1}+e_{\mathrm{t}}$

$[8] A M R_{t}=\beta_{0}+\beta_{1} I M A_{\mathrm{t}-1}+\beta_{2} U M R_{\mathrm{t}-1}+\beta_{3} A M R_{\mathrm{t}-1}+\beta_{4} G H E_{\mathrm{t}-1}+\beta_{5} I T N_{t-1}+\beta_{6} C F A_{t-1}+\beta_{7} P C I_{t-1}+e_{\mathrm{t}}$

[9] $G H E_{t}=\delta_{0}+\delta_{1} I M A_{\mathrm{t}-1}+\delta_{2} U M R_{\mathrm{t}-1}+\delta_{3} A M R_{\mathrm{t}-1}+\delta_{4} G H E_{\mathrm{t}-1}+\delta_{5} I T N_{\mathrm{t}-1}+\delta_{6} C F A_{\mathrm{t}-1}+\delta_{7} P C I_{\mathrm{t}-1}+e_{\mathrm{t}}$

[10] $I T N_{t}=\emptyset_{0}+\emptyset_{1} I M A_{\mathrm{t}-1}+\emptyset_{2} U M R_{\mathrm{t}-1}+\emptyset_{3} A M R_{\mathrm{t}-1}+\emptyset_{4} G H E_{\mathrm{t}-1}+\emptyset_{5} I T N_{\mathrm{t}-1}+\emptyset_{6} C F A_{\mathrm{t}-1}+\emptyset_{7} P C I_{\mathrm{t}-1}+e_{\mathrm{t}}$

[11] $C F A_{t}=\theta_{0}+\theta_{1} I M A_{\mathrm{t}-1}+\theta_{2} U M R_{\mathrm{t}-1}+\theta_{3} A M R_{\mathrm{t}-1}+\theta_{4} G H E_{\mathrm{t}-1}+\theta_{5} I T N_{\mathrm{t}-1}+\theta_{6} C F A_{\mathrm{t}-1}+\theta_{7} P C I_{\mathrm{t}-1}+e_{\mathrm{t}}$

[12] $P C I_{t}=\vartheta_{0}+\vartheta_{1} I M A_{\mathrm{t}-1}+\vartheta_{2} U M R_{\mathrm{t}-1}+\vartheta_{3} A M R_{\mathrm{t}-1}+\vartheta_{4} G H E_{\mathrm{t}-1}+\vartheta_{5} I T N_{\mathrm{t}-1}+\vartheta_{6} C F A_{\mathrm{t}-1}+\vartheta_{7} P C I_{\mathrm{t}-1}+e_{\mathrm{t}}$

Specifically, Equation [7] was used to achieve objective one of the study; Equation [8] was used to achieve objective two of the study; Equation [12] was used to achieve objective three of the study; and Equation [6] was used to achieve objective four of the study. However, in undergoing the VECM analysis, the unit root test for stationarity, cointegration test for long-run relationship among the variables, lag length analysis, VECM variance decomposition analysis for shock or effect responses, and stability test was carried out in the study.

\subsection{Presentation and Discussion of Results}

\subsubsection{Unit Root Test Result}

The result from Appendix 1 shows that all the time series data employed were not stationary at level. However, they became stationary at first difference.

\subsubsection{VECM Lag Length Result}

The result from Appendix 2 shows that the study uses the lag length criterion based on the Akaike information criterion (AIC), Schwarz information criterion (SC), and Hannan-Quinn information criterion (HQ) which all selected one lag for estimating the VECM and Johansen co-integration test.

\subsubsection{Co-Integration Test Result}

The result from Appendix 3 shows that both trace test statistics and max-eigen statistics indicates 6 co-integrating equations at the 5 percent level. On the basis of these tests, the conclusion that there exists a long-run relationship among the variables in the VECM model is made.

\subsubsection{VECM Variance Decomposition Test}

Research Question One: What is the Effect of Malaria Incidence on Adult Mortality Rate in Nigeria?

The variance decomposition of AMR on Appendix 4 indicates that a one standard deviation positive shock or innovation to IMA caused AMR to change by 0.5 percent in both the short-run and long-run. Other than own shock, IMA had 0.581684 percent and 0.574400 percent effects on AMR for periods 5 and 10 respectively representing both the short and long-run. This result shows that malaria incidence (IMA) had a positive but minimal effect on adult mortality rate (AMR) in Nigeria. This conforms to the findings of Nwanosikeet al (2015) which indicated that malaria cases impact on under-five mortality and adult mortality most especially, pregnant women in Nigeria.

Research Question Two: What is the Effect of Malaria Incidence on Under-Five Mortality Rate in Nigeria?

The variance decomposition of UMR on Appendix 5 indicates that a one standard deviation positive shock or innovation to IMA caused UMR to change by 0.8 percent in both the short and long-run. Other than own shock, IMA had 0.863524 percent and 0.853514 percent effects on UMR for periods 5 and 10 respectively representing both the short-run and long-run. Thus, this result shows that malaria incidence (IMA) had a positive but minimal effect on under-five mortality rate (UMR) in Nigeria. This conforms to the findings of Nwanosikeet al (2015) which indicated that malaria cases impact on under-five mortality, and the degree of the impact determines the effect of malaria prevalence on health outcome in Nigeria. 
Research Question Three: What is the Effect of Malaria Incidence on Human Per Capita Income in Nigeria?

The variance decomposition of PCI on Appendix 6 indicates that a one standard deviation positive shock or innovation to IMA caused PCI to change by 40.2 percent in the short-run and 40.6 percent in the long-run. Other than own shock, IMA had 40.25957 percent and 40.60006 percent effects on PCI for periods 5 and 10 respectively representing both the short-run and long-run respectively. Thus, this result shows that malaria incidence (IMA) had a positive but minimal effect on human per capita income (PCI) in Nigeria. This conforms to the findings of Yelwa and Diyoke (2014) which revealed that the prevalence of malaria leads to a slow growth in productivity and income per capita growth in Nigeria.

Research Question Four: What is the Effect of Malaria Control on Malaria Incidence in Nigeria?

The variance decomposition of IMA on Appendix 7 indicates that a one standard deviation positive shock or innovation to CFA caused IMA to change by 2.2 percent in the short-run and 1.4 percent in the long-run. Other than own shock, CFA had 2.215314 percent and 1.430718 percent effects on IMA for periods 5 and 10 respectively representing both the short-run and long-run respectively.

Consequently, one standard deviation positive shocks or innovation to GHE caused IMA to change by 38 percent in the short-run and 37 percent in the long-run. Other than own shock, GHE had 38.04693 percent and 37.96001 percent effects on IMA for periods 5 and 10 respectively representing both the short-run and long-run respectively.

Lastly, one standard deviation positive shocks or innovation to ITN caused IMA to change by 28.3 percent in the shortrun and 28.2 percent in the long-run. Other than own shock, ITN had 28.32944 percent and 28.21063 percent effects on IMA for periods 5 and 10 respectively representing both the short-run and long-run respectively.Therefore, the result from Appendix 7 shows that malaria control which comprises of children receiving anti-malarial drugs (CFA), government health expenditure (GHE), and insecticide-treated bed net (ITN) had a positive but minimal effect on malaria incidence (IMA) in Nigeria. This conforms to the findings of Amzat (2011) that malaria burden is still enormous because of inadequate control efforts, and that only $17 \%$ of Nigerians owned at least one net, compared with $12 \%$ in 2003; $8 \%$ owned an insecticide-treated mosquito net (ITN), but only $6 \%$ of under-five children and 5\% of pregnant women slept under an ITN; only one third of under-five children with fever received anti-malarial drugs, while one fifth of pregnant women took anti-malarial drugs for prevention in Nigeria.

\subsubsection{Autocorrelation Test}

The result of the VEC Residual Serial Correlation LM tests on Appendix 8 accepted the null hypothesis of no serial correlation since the probability of both lags were greater than the 5 per cent levels.

\subsubsection{Stability Test}

The Inverse roots of the AR polynomial graph in Appendix 9have roots with modulus which are less than one and they lie within the unit circle; it means that the model is stable and the variance decomposition standard errors would be valid and the conclusions of the model would also be reliable. Therefore, the VECM model satisfies the dynamic stability condition.

\subsection{Policy Implications}

The VECM estimates from the variance decomposition test showed that malaria incidence (IMA) had a positive but minimal effect on adult mortality rate (AMR) in Nigeria. The positive effect is implicative of the fact that an increase in malaria incidence leads to a minimal increase in adult mortality rate in Nigeria. This means that the prevalence of malaria cases is responsible for $0.5 \%$ death rates on adults in Nigeria. The VECM estimates from the variance decomposition test showed that malaria incidence (IMA) had a positive and minimal effect on under-five mortality rate (UMR) in Nigeria. The positive effect if also implicative of the fact that an increase in malaria incidence leads to minimal increase in under-five mortality rate in Nigeria. Thus, the prevalence of malaria cases is responsible for $0.8 \%$ death rate on children of under-five years of age in Nigeria. This also implies that; malaria incidence has led to more death rates on under-five aged children than the adults in Nigeria. And the degree of this impact determines the effect of malaria prevalence on general health outcome in Nigeria, which include low labour productivity. The VECM estimates from the variance decomposition test showed that malaria incidence (IMA) had a positive and minimal effect on per capita income (PCI) in Nigeria. The positive but minimal effect implies that an increase in malaria incidence leads to a minimal increase in per capita income, thus a low level of human productivity in Nigeria. This also implies that malaria prevalence resulted the total economic labour force and its level of productivity to only $40 \%$, which is a significant factor of poor human and economic development in Nigeria. This is because, less individuals stay out of work, and children staying out of school as a result of the malaria epidemic in Nigeria. 
The VECM estimates from the variance decomposition test showed that malaria control which consists of children receiving anti-malarial drugs (CFA), government health expenditure (GHE), and insecticide-treated bed nets (ITN) had a positive and minimal effect on malaria incidence (IMA) in Nigeria. Categorically, the positive and minimal effect of children receiving anti-malarial drugs on malaria incidence implies that an increase in children receiving anti-malarial drugs leads to an increase by $1.4 \%$ in malaria incidence in Nigeria. In other words, it implies that the anti-malarial drugs for children has not yet been able to reduce the incidence of malaria in Nigeria. Thus, anti-malarial drugs for children has not be adequately made available for children for treatments in order to reduce the prevalence of malaria in Nigeria.

On the other hand, the positive and minimal effect of government health expenditure on malaria incidence implies that an increase in government health spending leads to a minimal increase by $37 \%$ in malaria incidence in Nigeria. Thus, rather than government health expenditure to greatly reduce the prevalence of malaria, was instead found to increase the prevalence of malaria by $37 \%$ under the period of study. This would be as a result that the spending by the government on health, most especially on malaria cases was either inadequate or disrupted with issue of corruption, thereby making it impossible to adequately reduce the prevalence of malaria in Nigeria.

Lastly, the positive and minimal effect of insecticide-treated bed net (ITN) on malaria incidence implies that an increase in the provision of ITN leads to a very minimal increase by $28 \%$ in malaria incidence in Nigeria. Thus, rather than ITN to help in reducing the prevalence of malaria mostly among children and pregnant women, was instead found to increase the prevalence of malaria by $28 \%$ under the period of study. This would be as a result that there might be some leakages or diversion of funds meant for the provision of ITNs for some selfish interests, thereby also making it impossible for children especially under-five years of age and pregnant women to get access to ITNs for preventing and controlling the prevalence of malaria in Nigeria.

\subsection{Conclusion}

The study examined the effect of malaria incidence and malaria control on health outcome and human capital development in Nigeria from 1991 to 2017. In achieving the objectives of the study, vector error correction model (VECM) estimation technique was employed for the nature of the effects of the variables. The results of the analysis showed that malaria incidence had a positive but minimal effect on adult mortality rate, under-five mortality rate, and human per capita income. It also showed that malaria control which consists of children receiving anti-malarial drugs, government health expenditure, and insecticide-treated bed nets (ITNs) had a positive but poor effect on reducing the prevalence of malaria in Nigeria. Therefore, on the basis of findings of this study, it was revealed that Nigeria among other African nations is yet to fully reduce and effectively control the prevalence of malaria, thereby improving on positive health outcomes and sustainable national development.

\subsection{Recommendations}

Based on the findings and policy implications revealed from the analysis, the study therefore recommends the followings:

The current National Malaria Control Programme (NMCP) should be strengthened and given more impetus in order to effectively control and combat malaria, as this will be a conscious effort at reducing mortality rates and enhancing human capital development in Nigeria. The Federal Government of Nigeria should give major priority to the health sector in terms of spending, as doing otherwise has not been able to improve on positive health outcomes (i.e. reducing the prevalence of malaria) in Nigeria. This will increase the provision of health facilities and commodities, storage facilities, and provision of appropriate anti-malarial medicines that will aid in controlling and reducing malaria incidence in Nigeria.

Agencies such as Economic and Financial Crime Commission (EFCC) and Independent Corrupt Practices and Others Related Offences Commission (ICPC) which are established to fight corruption and any fraudulent acts, should be seen to do their jobs to checkmate and reduce the diversion of funds meant for the procurement and provision of insecticidetreated bed nets (ITNs) for children and adults most especially pregnant women in controlling and reducing the prevalence of malaria in Nigeria. In addition, there should be intensifies mass campaigns on the use and importance of ITNs, and massive free distribution of ITNs by various health and government agencies (i.e. Federal Ministry of Health) throughout the States of the nation, Government and relevant health policy makers should ensure timely availability and access to appropriate anti-malarial medicines, as well as other commodities required for prevention, control and treatment of malaria in Nigeria. In doing this, they should ensure effective and efficient procurementrelated processes; and developing efficient distribution systems for anti-malarial drugs and commodities, which may include transport distribution and inventory management. 


\section{References}

Abah, A. E., Awi-Waadu, G. D. B., Nduka, F. O., \& Richard, A. (2017). Malaria infection and socio-economic status of some residents of Port Harcourt metropolis, Rivers State, Nigeria. Journal of Applied Science, Environment and Management, 21(2), 299-304.

Abatan, S. M. \&Batunde, A. (2015). Empirical investigation into the patterns and trends of occurrences of malaria cases in Ekiti State, Nigeria: an analysis of the skewed ARMA. International Journal of Banking, Finance, Management and Development Studies, 3(1), 163-186.

Adepoju, K. A. \&Akpan, G. E. (2017). Historical assessment of malaria hazard and mortality in Nigeria-cases and deaths: 1955-2015. International Journal of Environment and Bioenergy, 12(1), 30-46.

Ajani, O. I. Y. \&Ashagidigbi, W. M. (2008). Effect of malaria on rural households' farm income in Oyo State, Nigeria. African Journal of Biomedical Research, 11, 259-266.

Amzat, J. (2011). Assessing the progress of malaria control in Nigeria. World Health and Population, 12(3), 42-51.

Aribodor, D. N., Ugwuanyi, I. K., \&Aribodor, O. B. (2016). Challenges to achieving malaria elimination in Nigeria. American Journal of Public Health Research, 4(1), 38-41.

Brems, H. (1968). The production function: quantitative economic theory. New York: Wiley, 62-74.

Carrington, A. (2001). Malaria: it's human impact, challenges, and control strategies in Nigeria. Harvard Health Policy Review, 2(2).

Chukwu, F. (2018). Eliminating malaria in Nigeria by 2030: a possibility or a mirage? Retrieved from www. famsanet.org on $27^{\text {th }}$ April, 2019.

Demographic and Health Survey (DHS) (2017). Nigeria demographic and health survey 2013. National Population Commission, Federal Republic of Nigeria, Abuja, Nigeria.

Federal Ministry of Health (FMOH) (2010). National malaria control programme: advocacy, communication and social mobilization strategic framework and implementation plan. Abuja: Federal Ministry of Health.

Federal Ministry of Health (FMOH) (2016). National malaria control programme: national malaria strategic plan 2012-2016. Abuja: Federal Ministry of Health.

Federal Ministry of Health (FMOH) (2017). National malaria strategic plan: 2014-2020 - Roll Back Malaria. Federal Republic of Nigeria, Abuja.

Grossman, M. (1972). On the concept of health capital and the demand for health. Journal of Political Economy, 80(2), 223-235.

Hulton, C. R. (2000). Total factor productivity: a short biography. NBER Working Paper No. 7471.

Jimoh, A. (2000). The malaria burden and agricultural output in Nigeria. Department of Economics, University of Ilorin, Nigeria.

Jimoh, A., Sofola, O., Petu, A., \&Okorosobo, T. (2007). Quantifying the economic burden of malaria in Nigeria using the willingness to pay approach. Cost Effectiveness and Resource Allocation, 5(6), 1-8.

Maduka, O. (2018). End malaria for good: a review of current strategies and future novelties for malaria elimination in Nigeria. Malaria World Journal, 9(1), 1-4.

Malaria Indicator Survey (MIS) (2010). Nigeria malaria indicator survey for 2010: final report. Abuja, Nigeria.

Malaria Indicator Survey (MIS) (2015). Nigeria malaria indicator survey for 2015: final report. Abuja, Nigeria.

National Malaria Control Programme (NCMP) (2012). Nigeria malaria indicator survey 2010. Abuja, Nigeria, NCMP International.

National Population Commission (NPC) (2006 Projected). A verbal/social autopsy study to improve estimates of the causes and determinants of neonatal and child mortality in Nigeria. National Population Commission, Abuja, Nigeria.

Nnadu, P. M., Peter, E., Alexander, P., Koggie, A. Z., \&Maikenti, J. I. (2015). The prevalence of malaria in children between the ages 2-15 visiting Gwarinpa general hospital life-camp, Abuja, Nigeria. Journal of Health Sciences, 5(3), 47-51.

Nwanosike, D. U., Ikpeze, I. N., \&Ugbor, I. K. (2015). Investigation of malaria prevalence and health outcome in Nigeria. ISOR Journal of Humanities and Social Science, 20(5), 79-84.

Nyiatagher, Z. I., Umeh, J. C., \& Ocholi, A. (2015). Socio-economic effects of malaria on households' consumption in north-central Nigeria. IOSR Journal of Agriculture and Veterinary Science, 8(7), 65-72.

Ogiri, A. E. (2017). Much ado about the 2018 health budget. Blueprint Newspapers Limited.

Olalekan, M. S. \& Nurudeen, A. S. (2013). Malaria burden and the effectiveness of malaria control measures in Nigeria: a case study of Asa local government area of Kwara State. Journal of Economics and Sustainable Development, 4(3), 295-308. 
President's Malaria Initiative (PMI) (2018). Nigeria malaria operational plan FY 2018. Retrieved from www.pmi.gov on $27^{\text {th }}$ April, 2019.

Tewari, D. D., Braimoh, L. A., \&Bokana, K. G. (2009). Factors affecting malaria epidemics and its economic impacts on households in Ajegunle, Lagos State in Nigeria. The Journal of Interdisciplinary Economics, 21, 79-96.

Usman, A. \& Adebayo, M. O. (2011). Socio-economic impact of malaria epidemics on households in Nigeria: micro evidence from Kwara State. International Journal of Asian Social Sciences, 1(5), 188-196.

Wagstaff, A. (1986). The demand for health: theory and application. Journal of Epidemiology and Community Health, 40(1), 2.

Wibowo, D. \&Tisdell, C. (1992). Health production function for preventive health programs. Proceedings of the Fourteenth Australian Conference of Health Economists, p. 106-133, Faculty of Economics, Commerce and Management Monash University and National Centre for Health Program Evaluation Fairfield Hospital.

Yelwa, M. \&Diyoke, K. O. (2014). Empirical analysis of the incidence of malaria on human capital development and economic growth in Nigeria. Retrieved from www.researchgate.net/publication.

World Health Organization (WHO) (2016). World malaria report 2016. Geneva: World Health Organization.

\section{Appendices}

Appendix 1: Augmented Dickey-Fuller Unit Root Test Result

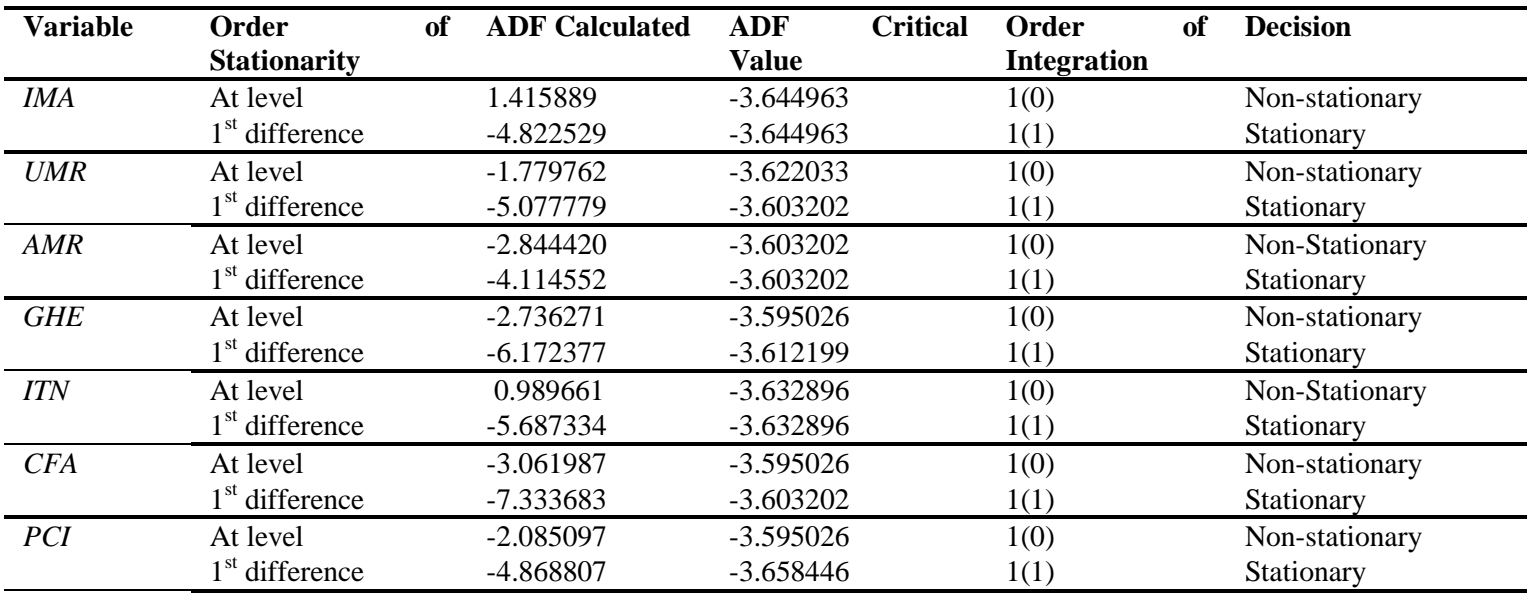

Computed at $5 \%$ ADF critical value

Appendix 2:VAR Lag Order Selection Criteria

\begin{tabular}{lllllll}
\hline Lag & LogL & LR & FPE & AIC & SC & HQ \\
\hline 0 & -830.3103 & NA & $2.21 \mathrm{e}+19$ & 64.40848 & 64.74720 & 64.50602 \\
1 & -563.5167 & $369.4065^{*}$ & $1.35 \mathrm{e}+12 *$ & $47.65513^{*}$ & $50.36488^{*}$ & $48.43544 *$ \\
\hline
\end{tabular}

* indicates lag order selected by the criterion

LR: sequential modified LR test statistic (each test at $5 \%$ level)

FPE: Final prediction error

AIC: Akaike information criterion

SC: Schwarz information criterion

HQ: Hannan-Quinn information criterion

\section{Appendix 3: Johansen Co-Integration Test Result}

\begin{tabular}{|c|c|c|c|c|c|}
\hline $\begin{array}{l}\text { No. of } \\
\text { CE(S) }\end{array}$ & $\begin{array}{l}\text { Trace } \\
\text { stat. }\end{array}$ & $\begin{array}{l}0.05 \% \\
\text { CV }\end{array}$ & $\begin{array}{l}\text { No. of } \\
\text { CE(S) }\end{array}$ & $\begin{array}{l}\text { Max-Eigen } \\
\text { Stat. }\end{array}$ & $\begin{array}{l}0.05 \% \\
\text { CV }\end{array}$ \\
\hline None $*$ & 365.8056 & 125.6154 & None $*$ & 108.8649 & 46.23142 \\
\hline At most $1 *$ & 256.9407 & 95.75366 & At most $1 *$ & 85.06381 & 40.07757 \\
\hline At most $2 *$ & 171.8769 & 69.81889 & At most $2 *$ & 71.08675 & 33.87687 \\
\hline At most $3 *$ & 100.7902 & 47.85613 & At most $3 *$ & 49.51850 & 27.58434 \\
\hline At most $4 *$ & 51.27167 & 29.79707 & At most $4 *$ & 29.19627 & 21.13162 \\
\hline At most $5 *$ & 22.07540 & 15.49471 & At most $5 *$ & 20.50083 & 14.26460 \\
\hline At most $6 *$ & 1.574562 & 3.841466 & At most $6^{*}$ & 1.574562 & 3.841466 \\
\hline
\end{tabular}

*denotes rejection of the hypothesis at the 5\% 
Appendix 4:Results of Variance Decomposition Analysis of Adult Mortality Rate (AMR)

\begin{tabular}{lllllllll}
\hline Period S.E. & AMR & CFA & GHE & IMA & ITN & PCI & UMR \\
\hline 1 & 3.352796 & 100.0000 & 0.000000 & 0.000000 & 0.000000 & 0.000000 & 0.000000 & 0.000000 \\
2 & 6.789828 & 97.58820 & 0.096809 & 0.468633 & 0.987706 & 0.766250 & 0.067887 & 0.024517 \\
3 & 9.962429 & 95.25013 & 0.335173 & 0.243218 & 1.020563 & 2.756035 & 0.239791 & 0.155088 \\
4 & 13.14439 & 95.51589 & 0.208391 & 0.142827 & 0.793543 & 2.582421 & 0.313871 & 0.443052 \\
5 & 15.86878 & 94.36942 & 0.148758 & 0.245641 & 0.581684 & 2.941751 & 0.704083 & 1.008665 \\
6 & 18.20235 & 92.75126 & 0.113924 & 0.265772 & 0.575038 & 3.468876 & 1.109179 & 1.715954 \\
7 & 20.18812 & 90.90007 & 0.102214 & 0.304655 & 0.664975 & 3.754942 & 1.598736 & 2.674406 \\
8 & 21.87979 & 88.73884 & 0.184174 & 0.543952 & 0.589351 & 3.884782 & 2.199503 & 3.859402 \\
9 & 23.26816 & 85.97023 & 0.248841 & 0.799286 & 0.573966 & 4.201675 & 2.959131 & 5.246872 \\
10 & 24.44248 & 83.22084 & 0.344437 & 1.023413 & 0.574400 & 4.367642 & 3.701260 & 6.768010 \\
\hline
\end{tabular}

Appendix 5:Results of Variance Decomposition Analysis of Under-five Mortality Rate (UMR)

\begin{tabular}{lllllllll}
\hline Period S.E. & AMR & CFA & GHE & IMA & ITN & PCI & UMR \\
\hline 1 & 0.274787 & 3.657897 & 7.883727 & 7.223291 & 5.135105 & 1.034395 & 19.49503 & 55.57056 \\
2 & 0.650635 & 12.46015 & 7.189744 & 9.207129 & 2.572920 & 0.185076 & 19.57762 & 48.80736 \\
3 & 1.144018 & 22.42133 & 6.540639 & 9.231254 & 1.448072 & 0.081174 & 17.80059 & 42.47694 \\
4 & 1.748948 & 31.27093 & 6.108113 & 8.812366 & 1.009884 & 0.037670 & 15.85373 & 36.90731 \\
5 & 2.442531 & 38.72068 & 5.743914 & 8.232631 & 0.863524 & 0.026374 & 14.02862 & 32.38425 \\
6 & 3.201843 & 44.80459 & 5.401684 & 7.652721 & 0.797689 & 0.046763 & 12.51405 & 28.78251 \\
7 & 4.002982 & 49.63811 & 5.136492 & 7.171255 & 0.797006 & 0.094916 & 11.25850 & 25.90372 \\
8 & 4.826100 & 53.54766 & 4.901822 & 6.770977 & 0.810648 & 0.150531 & 10.24364 & 23.57472 \\
9 & 5.649368 & 56.72483 & 4.702461 & 6.425776 & 0.831371 & 0.212580 & 9.410961 & 21.69202 \\
10 & 6.458390 & 59.32028 & 4.532182 & 6.135162 & 0.853514 & 0.275502 & 8.729102 & 20.15426 \\
\hline
\end{tabular}

Appendix 6:Results of Variance Decomposition Analysis of Per Capita Income (PCI)

\begin{tabular}{lllllllll}
\hline Period & S.E. & AMR & CFA & GHE & IMA & ITN & PCI & UMR \\
\hline 1 & 202.8444 & 0.000908 & 1.059014 & 0.102461 & 18.22471 & 72.02832 & 8.584584 & 0.000000 \\
2 & 385.3871 & 0.017404 & 8.698937 & 23.93506 & 39.64567 & 25.08826 & 2.469941 & 0.144728 \\
3 & 413.9412 & 3.212234 & 7.621478 & 25.52188 & 39.32104 & 21.96307 & 2.203380 & 0.156918 \\
4 & 424.3747 & 4.046857 & 7.306557 & 25.21194 & 37.82373 & 23.03832 & 2.387601 & 0.184995 \\
5 & 501.8089 & 3.160311 & 8.040168 & 24.80070 & 40.25957 & 21.58098 & 1.988486 & 0.169784 \\
6 & 530.6870 & 4.665417 & 7.449864 & 26.00746 & 40.09392 & 19.73519 & 1.801691 & 0.246453 \\
7 & 546.5423 & 4.765642 & 7.093417 & 25.18307 & 39.52553 & 20.59449 & 2.323441 & 0.514405 \\
8 & 580.4669 & 4.358975 & 7.005811 & 25.23782 & 39.84132 & 20.60418 & 2.315699 & 0.636190 \\
9 & 611.2857 & 4.080090 & 6.736621 & 25.38094 & 40.85156 & 19.72510 & 2.356377 & 0.869315 \\
10 & 622.7944 & 4.031221 & 6.501560 & 25.23720 & 40.60006 & 19.80525 & 2.621594 & 1.203110 \\
\hline
\end{tabular}

Appendix 7:Results of Variance Decomposition Analysis of Incidence of Malaria (IMA)

\begin{tabular}{lllllllll}
\hline Period & S.E. & AMR & CFA & GHE & IMA & ITN & PCI & UMR \\
\hline 1 & 18.70485 & 0.735849 & 6.491279 & 28.88082 & 63.89205 & 0.000000 & 0.000000 & 0.000000 \\
2 & 25.38949 & 4.189090 & 3.760246 & 32.14431 & 35.14893 & 22.58579 & 2.134895 & 0.036738 \\
3 & 28.66622 & 4.470754 & 3.070055 & 34.91349 & 27.96376 & 27.57001 & 1.982596 & 0.029344 \\
4 & 33.52576 & 7.768102 & 2.512207 & 37.69700 & 21.24249 & 28.25995 & 2.473914 & 0.046341 \\
5 & 37.12441 & 10.46464 & 2.215314 & 38.04693 & 18.60902 & 28.32944 & 2.287845 & 0.046819 \\
6 & 40.14014 & 13.81246 & 1.895452 & 37.06579 & 15.97628 & 28.97012 & 2.226693 & 0.053210 \\
7 & 42.95423 & 14.85361 & 1.909658 & 37.98793 & 15.43971 & 27.69158 & 2.022049 & 0.095459 \\
8 & 46.04955 & 16.57350 & 1.679777 & 37.86397 & 13.93285 & 27.85836 & 1.944104 & 0.147440 \\
9 & 48.14511 & 17.41377 & 1.544650 & 37.72781 & 13.10984 & 28.11974 & 1.801070 & 0.283120 \\
10 & 50.28295 & 17.88959 & 1.430718 & 37.96001 & 12.40967 & 28.21063 & 1.695440 & 0.403951 \\
\hline
\end{tabular}


Appendix 8:VEC Residual Serial Correlation LM Tests Result

Null hypothesis: No serial correlation at lag $h$

\begin{tabular}{lccccll}
\hline Lag & LRE* stat & Df & Prob. & Rao F-stat & df & Prob. \\
\hline 1 & 53.51194 & 49 & 0.3052 & 0.984973 & $(49,19.7)$ & 0.5374 \\
\hline Null hypothesis: No serial correlation at lags 1 to h & & \\
\hline Lag & LRE* stat & Df & Prob. & Rao F-stat & df & Prob. \\
\hline 1 & 53.51194 & 49 & 0.3052 & 0.984973 & $(49,19.7)$ & 0.5374 \\
\hline
\end{tabular}

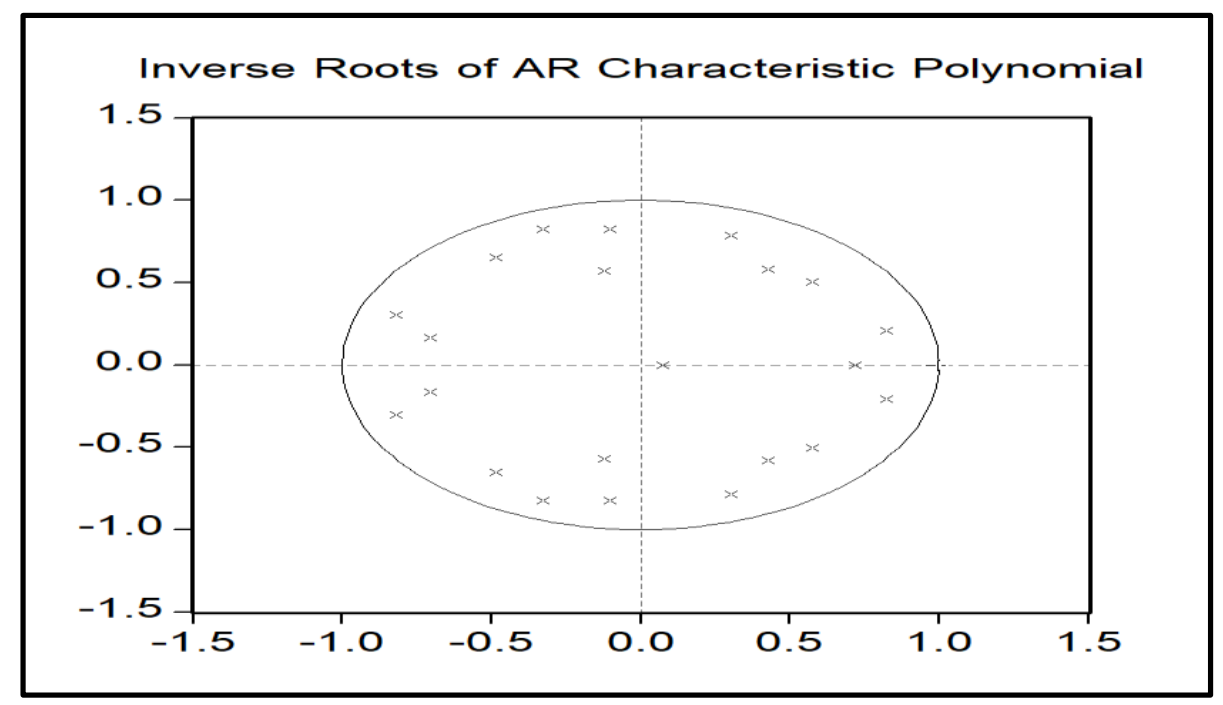

Appendix 9: VECM Stability Test Result 